\title{
Stimulus control of behavior during the postreinforcement pause of FI schedules
}

\author{
NANCY K. INNIS \\ University of Western Ontario, London, Ontario N6A 5C2, Canada \\ and \\ WERNER K. HONIG \\ Dalhousie University, Halifax, Nova Scotia, Canada
}

\begin{abstract}
Pigeons were given the opportunity to terminate certain segments of fixed intervals by pecking a control key. When 30 -sec segments of negative and positive stimuli alternated across the interreinforcement interval (Experiment 1), most birds terminated a large proportion of negative segments. However, few control-key responses were made during the negative segment immediately following food presentation. Under schedules during which only one negative segment was programmed, during the first $30 \mathrm{sec}$ of 1 -min intervals (Experiment 2), control-key responses, when they occurred at all, were made after several seconds of the interval had elapsed. Similar findings were obtained when a peck on the control key merely changed the color on the food key (Experiment 3). These findings suggest that the postreinforcement extinction state (Schneider, 1969) during fixed-interval schedules consists of two phases: an immediate postreinforcement inhibitory phase, followed by a second phase during which a control-key response may occur. These two phases and their associated behavior may be related to Staddon's (1977) distinction between interim and facultative activities.
\end{abstract}

The behavior of pigeons on fixed-interval (FI) schedules of reinforcement develops a characteristic pattern, the FI scallop (Ferster \& Skinner, 1957). Toward the end of an interreinforcement interval, a high rate of keypecking, the terminal response, is usually observed, while at times immediately following food presentation, other behaviors, called interim activities, are likely to occur (Staddon, 1977; Staddon \& Simmelhag, 1971). The period during which behavior other than the required operant (terminal response) occurs is called the postreinforcement pause and is typically a constant proportion of the interreinforcement interval (Schneider, 1969). Schneider suggests that the two states reflected in the pause and keypecking behavior of pigeons on FI schedules are comparable to those underlying performance on multiple extinction variable-interval (mult EXT VI) schedules. If this analysis is correct, birds might be expected to show similar behavior during the interim period of FI schedules and the extinction component of a mult EXT VI schedule.

Although there are relatively few studies of be-

Experiments 1 and 2 were supported by National Research Council Grant APT-102 to W. K. Honig, and Experiment 3 and preparation of the manuscript by National Research Council Grant A-9945 to N. K. Innis. The authors thank Heather Lindsay and Debra Dawson for assistance in running the birds and Robert Dale for comments on the manuscript. Reprints may be obtained from Nancy K. Innis, Department of Psychology, University of Western Ontario, London, Ontario N6A 5C2, Canada. havior other than the terminal response on either FI or mult EXT VI schedules, some researchers have suggested that pigeons find stimuli associated with both extinction and the early portions of FI schedules aversive. Terrace (1966) reported that birds showed "emotional" responses, such as wingflapping, during the extinction component of a multiple schedule, and Azrin et al. (1966) found that pigeons would attack a target bird during extinction. Richards and Rilling (1972) obtained similar target-attack behavior in pigeons on an FI 90-sec schedule. Most of the attacks were recorded during the first half of an interreinforcement interval.

Birds will also respond to terminate visual stimuli associated with both FI and extinction schedules. Brown and Flory (1972) found that pigeons would respond to change the color of the key light and turn off the houselight during fixed intervals ranging from 30 to $960 \mathrm{sec}$, although interval duration was not shortened by this response. Rilling et al. (1969) found that pigeons would peck a key to produce a blackout and thus escape from a stimulus associated with extinction. Honig and his associates (Honig et al., 1972; Leyland \&.Honig, 1975) showed that birds would learn a control-key response to terminate extinction components and produce VI components on mult EXT VI schedules.

If performance on FI schedules reflects control by periods of extinction and variable-interval reinforcement as Schneider (1969) suggests, it might be ex- 
pected that pigeons would learn to peck a control key to terminate stimuli, both temporal and exteroceptive, associated with extinction periods on FI schedules. The experiments reported here examined this possibility.

\section{EXPERIMENT 1}

\section{Method}

\section{Subjects}

Four White Carneaux pigeons were maintained at approximately $80 \%$ of their free-feeding weights throughout the experiment. Birds 20 and 22 had previous experience in a conceptdiscrimination study; Birds 5 and 6 had been trained on a cyclic fixed-interval schedule.

\begin{abstract}
Apparatus
A standard three-key Grason-Stadler operant conditioning chamber, with in-line projectors mounted behind the left and center keys, was housed in a large wooden box to reduce extraneous sound transmission. Pecks on the center (food) key, which could be illuminated with red or green light, occasionally produced about 7 -sec access to mixed grain. When the left key was illuminated with white light, a response on it changed the color of the stimulus on the center key and advanced the schedule to the next 30 -sec period. The chamber was illuminated with a houselight which, along with the key lights, was extinguished during food presentation, when the only illumination was provided by a light over the feeder.

Programming and recording equipment was in an adjoining room. Data were recorded on digital counters and a cumulative recorder. During some sessions, the latencies of control-key responses were recorded on a printing counter.
\end{abstract}

\section{Procedure}

The basic procedure involved a nominal FI 4-min schedule of reinforcement, during which different stimuli were associated with alternating 30-sec (actually 28.7-sec) segments of an interval (cf. Dews, 1962). For Birds 20 and 5, during the first, third, fifth, and seventh segments, the food-key light was red $\left(\mathrm{S}^{\Delta}\right)$, and during the second, fourth, sixth, and eighth segments it was green $\left(\mathrm{S}^{\mathrm{D}}\right)$. Following the end of the eighth segment, the key light remained green until the first peck occurred, producing access to food. For Birds 22 and 6, stimulus significance was reversed. Twenty fixed intervals, that is $80 \mathrm{~S}^{\Delta}$ and $80 \mathrm{~S}^{D}$ segments, comprised each daily session.

The experimental conditions experienced by each bird are listed in Table 1. Following 31 sessions on the baseline FI 4-min schedule, the control-response dependency was introduced. During the four segments of $S^{\Delta}$, the left key was illuminated with white light, and a peck on this key terminated the $S^{\Delta}$ and advanced the bird to the next scheduled $\mathrm{S}^{\mathrm{D}}$ segment. Thus, pecks on the left key, as well as providing an opportunity for birds to escape from $S^{\Delta}$, also shortened the interreinforcement interval; for example, if a bird made a control-key peck at the outset of each $\mathrm{S}^{\Delta}$ period, the total interreinforcement interval would be reduced to half its original length.

After a return to baseline (Condition 3), conditions with the control key lighted and operative only during $S^{D}$ segments (Condition 4) and then throughout the session (Condition 5) were conducted. When the control key was operative during SD, a control key response advanced the bird to the next $\mathrm{S}^{\Delta}$ segment. A controlkey peck during the final segment of an interval recycled the animal to the start of the next interval (omitting reinforcement). Finally, in Condition 6 , the birds were again returned to the $S^{\Delta}$. only control-key condition.

\section{Results and Discussion}

The birds readily came under the control of the stimuli associated with the positive (SD) and negative $(\mathrm{S} \Delta)$ segments of the fixed interval. As Figure 1 shows, very few food-key pecks occurred during the four $\mathrm{S}^{\Delta}$ segments (black bars), while the number of responses increased systematically across the four $\mathrm{SD}$ segments of an interval (white bars). Data are plotted in the form of histograms, with responding in each segment being given as a proportion of the number of responses in the final segment of the interval. Data are means across four birds over the last five sessions of each condition. All subjects showed similar patterns of responding, so these means are highly representative of each individual subject's performance. The overall pattern of responding was similar for all conditions of the experiment; the main difference was that fewer responses occurred in the first two SD segments during Conditions 2,5 , and 6 , that is, when the control key was operative during $\mathrm{S}^{\Delta}$ segments (histograms in lower half of Figure 1).

The latency to peck the food key during each segment of an interval changed both as a function of the stimulus conditions and the position of the segment within an interval. The histograms on the left in Figure 2 show the average time to the first peck on the food key during all segments of intervals in Condition 1. The data, for individual birds, are aver-

Table 1

Experimental Conditions, Number of Sessions per Condition, Component during which the Control Key was Operative, Percent of Segments of Intervals Terminated by a Control-Key Response, and, in Parenthesis, the Total Number (of a Possible 400) Control-Key Responses During the Last Five Sessions of Each Condition of Experiment 1

\begin{tabular}{|c|c|c|c|c|c|c|}
\hline \multirow[b]{3}{*}{ Condition } & \multirow[b]{3}{*}{ Sessions } & \multirow[b]{3}{*}{ Control Key } & \multicolumn{4}{|c|}{ Percent Segments Terminated } \\
\hline & & & \multicolumn{4}{|c|}{ Birds } \\
\hline & & & 20 & 22 & 5 & 6 \\
\hline 1 & 31 & No & & & & \\
\hline 2 & 23 & $\mathrm{~S}^{\Delta}$ Only & $11(45)$ & $79(316)$ & $60(239)$ & $73(292)$ \\
\hline 3 & 15 & No & & & & \\
\hline 4 & 15 & SD Only & $0(0)$ & $3(12)$ & $0(0)$ & $0(1)$ \\
\hline & & $\mathrm{S}^{\Delta}$ Intervals & $1(5)$ & $43(173)$ & $19(76)$ & $58(230)$ \\
\hline 5 & 29 & $S^{D}$ Intervals & $0(1)$ & $6(24)$ & $0(1)$ & $3(11)$ \\
\hline 6 & 11 & $\mathrm{~S}^{\triangle}$ Only & $0(0)$ & $66(265)$ & $32(129)$ & $59(234)$ \\
\hline
\end{tabular}




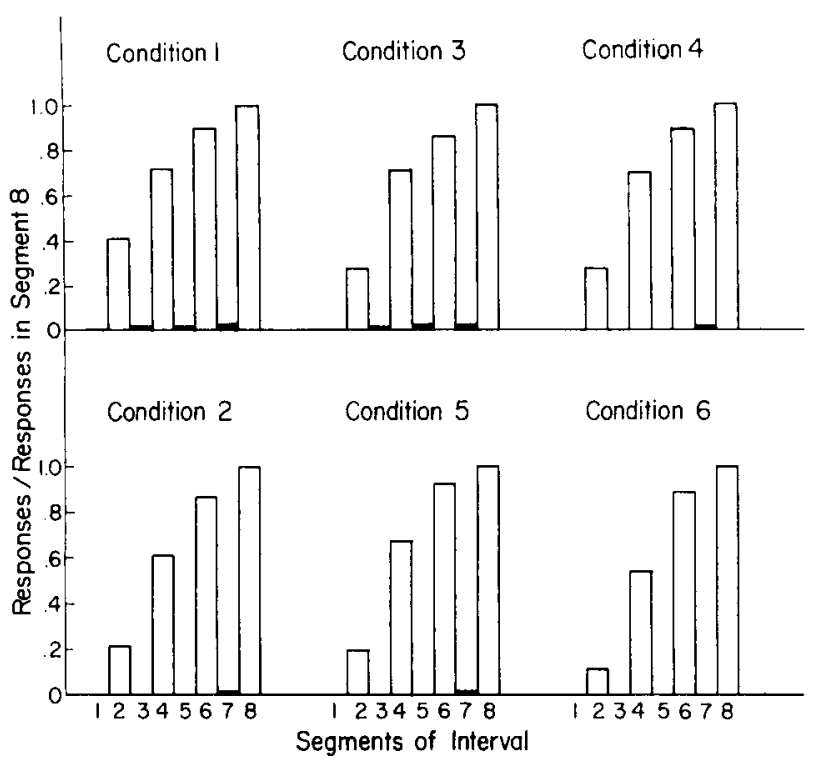

Figure 1. Food-key responses during each of the eight segments of interreinforcement intervals for the six conditions of Experiment 1 . The number of responses during each segment of an interval is given as a proportion of the number of responses during the final segment. Data are means across four birds over all intervals of the last five sessions of each condition. The black bars represent responding during $\mathrm{S}^{\Lambda}$ segments; the white bars, responding during SD segments.

aged over the last five sessions of the condition. If no food-key response occurred, then the time recorded was equal to the duration of the segment. Latencies were consistently shorter during SD segments (white bars) than during $\mathrm{S}^{\Delta}$ segments (black bars). The birds rarely responded during the first $\mathrm{S} \Delta$ segment, as indicated by a latency of approximately $28.7 \mathrm{sec}$, which was the actual duration of each " $30-\mathrm{sec}$ " segment.

The histograms on the right in Figure 2 show the latencies to respond on the food key across interval segments for Condition 2. Again, if no food-key response was made, the time recorded was equal to the segment duration. During this condition, with the control key operative, three of the four birds terminated many of the $\mathrm{S}^{\Delta}$ segments before a food-key peck had occurred in that segment, Thus, for all the $\mathrm{S} \Delta$ segments of Condition 2, the times recorded in the figure mainly represent segment duration rather than latency to peck the food key.

In both Condition 1 and Condition 2 the postreinforcement pause (time to the first peck on the food key in an interval) was usually between 30 and $50 \mathrm{sec}$, with the first peck occurring during the second segment of the interval in the presence of $S D$. Pauses tended to be consistently longer during Condition 2 than during Condition 1 , as indicated by the substantial increase in latencies recorded during this second segment of intervals in Condition 2.

The percent of segments terminated by a controlkey response during the last five sessions of each condition is shown in Table 1. Also included is the total number (of a possible 400) control-key responses made. In each session there were 80 opportunities to terminate segments during each stimulus in which the control key was operative. At the beginning of Condition 2, Birds 22, 5, and 6 were terminating about $90 \%$ of the $S \Delta$ segments; however, responding during the first segment soon dropped out. The birds continued to respond in this manner, as the data in Table 1 show, terminating a large proportion, but rarely more than $75 \%$, of segments. Bird 20 used the control key less frequently, terminating up to $40 \%$ of segments early in the condition and only $11 \%$ during the last 5 days.

When the control key was operative in SD periods only (Condition 4), all the birds virtually stopped pecking it by the end of the condition. In Condition 5 , when control-key responses were effective throughout the session, few responses occurred during SD segments, and the number of responses during $S^{\Delta}$ segments was somewhat depressed in comparison with the $\mathrm{S}^{\Delta}$-only conditions. Finally, during Condition 6 , with the control key again available only in $S^{\Delta}$ segments, the percentage of segments which were terminated increased, but not to the level of Condition 2 .

The three birds that consistently terminated $\mathrm{S}^{\Delta}$ segments showed a consistent pattern in control-key behavior across the fixed interval. Table 2 gives the mean percent time (of a possible $9.45 \mathrm{~min} / \mathrm{session}$ ) spent in each of the four $S^{\Delta}$ segments of an interval for Conditions 2, 5, and 6, the conditions during which the control key was operative during $S \Delta$ segments. Data are means for individual birds across all 20 intervals of each of the last five sessions of

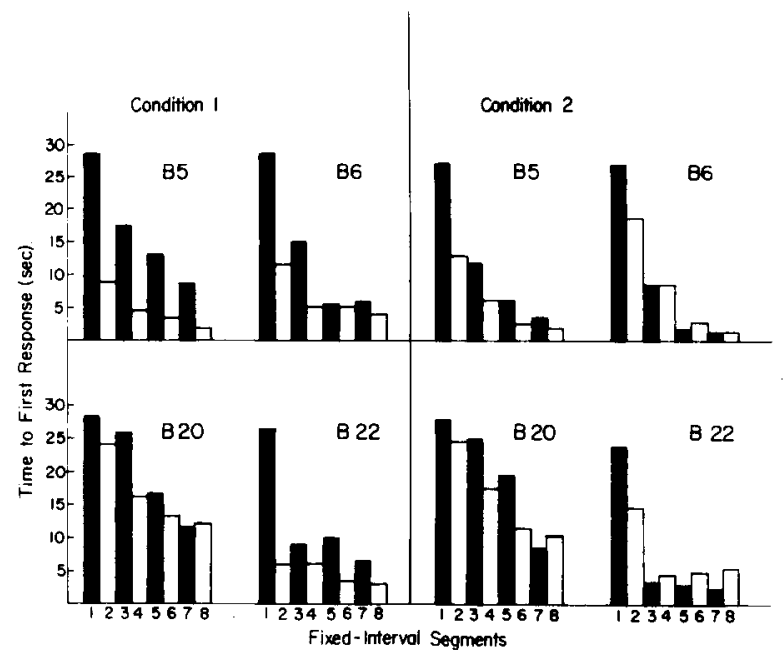

Figure 2. Mean time (in seconds) to respond on the food key during each segment of an interval or to the termination of a segment if no food-key peck occurred for each bird for Conditions 1 and 2 . Since each segment was actually 28.7 sec in duration, bars of the histograms of this height indicate no response. Data for the $S^{\Delta}$ segments are represented by black bars; for $S^{D}$ segments, by white bars. Data are means over the 20 intervals of each of the last five sessions of each condition. 
Table 2

Mean Percent Time (of a Possible 9.45 Minutes) Spent in Each $S^{\triangle}$ Segment of the Fixed Interval

\begin{tabular}{crrrrc}
\hline & & \multicolumn{4}{c}{$S^{\triangle}$ Segments } \\
\cline { 3 - 6 } & Bird & 1 & 2 & 3 & 4 \\
\hline \multirow{4}{*}{ Condition 2 } & 20 & 100 & 98 & 86 & 75 \\
& 5 & 86 & 19 & 19 & 15 \\
& 6 & 95 & 55 & 30 & 21 \\
& $\bar{X}$ & $95(93)$ & $51(35)$ & $36(19)$ & $30(14)$ \\
& 20 & 100 & 100 & 99 & 99 \\
Condition 5 & 22 & 98 & 77 & 58 & 56 \\
& 5 & 100 & 96 & 77 & 66 \\
& 6 & 96 & 59 & 35 & 36 \\
& $\bar{X}$ & $99(98)$ & $83(77)$ & $67(57)$ & $64(53)$ \\
& 20 & 100 & 100 & 100 & 100 \\
Condition 6 6 & 22 & 98 & 58 & 23 & 18 \\
& 5 & 100 & 93 & 64 & 43 \\
& 6 & 100 & 54 & 24 & 25 \\
& $\bar{X}$ & $100(99)$ & $76(68)$ & $53(37)$ & $47(29)$ \\
\hline
\end{tabular}

Note-Data are means over the 20 intervals of a session for the last five sessions of each condition. The numbers in brackets are the overall means excluding the data for Bird 20.

each condition, and overall means, including and excluding the data for Bird 20. As the data in the table show, the birds rarely terminated the initial Su segment, while the amount of time spent in subsequent $\mathrm{S} \Delta$ segments decreased systematically across the interval. Control-key pecks occurred during more segments and with shorter latencies across successive segments of an interval. Bird 20 pecked the control key infrequently, although in the above manner, during Condition 2 , and rarely made controlkey responses during subsequent conditions.

Although three of the four birds maintained high levels of control-key responding during the last three $\mathrm{S} \Delta$ segments of this FI 4-min schedule, pecks on the control key rarely occurred during the first $S^{\Delta}$ segment of an interval. There are at least two possible explanations for the failure of birds to terminate these $\mathrm{S}^{\Delta}$ periods. Responding on the control key may be directly reinforced, after various delays, by the primary reinforcer at the end of the interval, and the delay of reinforcement simply may be too great to maintain responding this early in the interval. The data presented in Table 2 support this view to some extent; the birds spent less time in the presence of $\mathrm{S} \Delta$ across successive segments of intervals, pecking the control key more often, and with shorter latencies, as time in the interval passed.

A second possibility is that the immediate aftereffects of food presentation result in a direct inhibition of pecking early in intervals. Staddon and Simmelhag (1971) have suggested that food-related responses are suppressed and activities corresponding to other motivational systems facilitated immediately following food presentation on temporally regular schedules. Only after some time has elapsed in the interval do the birds come under the control of the discriminative stimuli associated with the positive and negative components of the schedule, at which time they respond to terminate $S^{\Delta}$. This view is not inconsistent with the data presented in Table 2, since a delay-of-reinforcement gradient may operate once control by the discriminative stimuli begins.

In order to determine if a postfood inhibitory period does exist, the birds from this present study, along with four additional birds, were exposed to an FI 1-min schedule in Experiment 2. If the lack of control-key responding during the first $\mathrm{S} \Delta$ segment on the FI 4-min schedule were simply the result of the delay in reinforcement, one might expect the birds to respond on the control key during the FI 1-min schedule with very short latencies, of about 2 to $4 \mathrm{sec}$, comparable to those observed during the final $\mathrm{S} \Delta$ segment on the FI 4-min schedule (see Figure 2, Condition 2).

\section{EXPERIMENT 2}

\section{Method}

\section{Subjects}

Eight adult, male White Carneaux pigeons were maintained at $80 \%$ of their free-feeding weights throughout the experiment. The birds in Group $1(5,6,20$, and 22$)$ were studied in the previous experiment. The birds in Group $2(52,53,54$, and 58) also had had previous experience, involving either cyclic fixedtime or fixed-interval schedules.

\section{Apparatus}

The apparatus was similar to that used in Experiment 1. Pecks on the center (food) key, which could be illuminated with red or green light, occasionally produced $3-\mathrm{sec}$ access to mixed grain. When the left (control) key was illuminated with white light, a response on it turned off the white light and changed the color of the center key and/or reduced the time remaining in the interval to $30 \mathrm{sec}$.

\section{Procedure}

Group 1. Each daily session consisted of 45 one-min intervals, each programmed as two $30-\mathrm{sec}$ segments. For Birds 5 and 20 , red and green center-key lights were associated with the first $\left(\mathrm{S}^{\Delta}\right)$ and second $\left(\mathrm{S}^{\mathrm{D}}\right)$ segments of the interval, respectively. The light changed from red to green automatically after $30 \mathrm{sec}$, and remained green until the first peck after the FI 1-min interval had timed out. For Birds 6 and 22, the color of the center key was green in $\mathrm{S}^{\Delta}$ and red in $\mathrm{SD}^{\mathrm{D}}$. This schedule can be designated multiple extinction fixed-interval $30 \mathrm{sec}$ (mult EXT FI $30 \mathrm{sec}$ ). During the first 30 -sec segment $\left(\mathrm{S}^{\Delta}\right)$ of each interval, the left (control) key was illuminated with white light. A peck on this key turned off the white key light, terminated the $S^{\Delta}$ on the center key, and advanced the bird to the second 30-sec segment $\left(S^{D}\right)$ of the interval. Birds 5, 6, and 22 received 24 sessions, and Bird 20, 9 sessions, on this schedule.

Group 2. In the first session, Birds 52 and 53 were trained by the method of successive approximations to peck the center key and Birds 54 and 58 were habituated to the experimental chamber. The next day, all birds were exposed to an FI 1-min schedule (Bird 53 required some additional keypeck training at the start of the session) similar to that described for Group 1. For Birds 53 and 58, red and green center-key lights were associated with 
the first $\left(\mathrm{S}^{\Delta}\right)$ and the second $\left(\mathrm{S}^{D}\right)$ segments of an interval, respectively (mult EXT FI $30 \mathrm{sec}$ ); for Birds 52 and 54, the center key was red throughout the entire interval, that is, during both $30-$ sec segments. This schedule could be designated mixed EXT FI $30 \mathrm{sec}$.

During Condition 1, which lasted for 27 sessions, the left key remained dark and inoperative. In Condition 2 , the intervalcontrol dependency was introduced on the left key; a peck on this control key turned off the white light and advanced the program into the second $30-\mathrm{sec}$ segment of the interval. For Birds 53 and 58, pecks on the control key also resulted in a change in the color of the center (food) key from red to green. Condition 2 continued for 21 sessions. In Condition 3, the stimulus conditions on the food key were changed; for Birds 53 and 58 , the key was green throughout the interval, while for Birds 52 and 54 , the key was green during the first segment of the interval and red during the second segment. The control key was also operative in this final condition, which lasted for 21 sessions.

\section{Results and Discussion}

All the birds in Group 2 were showing stable fixedinterval performance at the end of Condition 1. Three of the birds were pausing about 33-34 sec before responding on the food key; Bird 54 (on the mixed schedule) had an average pause of $18 \mathrm{sec}$ over the last five sessions of the first condition. When the control key was introduced, all birds responded on it to some extent during the first few sessions of the condition, as was also the case with the birds in Group 1 . Data from the last five sessions of control-key conditions are presented in Table 3. Results from both mixed and multiple schedule conditions are included for Group 2, although the multiple schedule data are of most interest. Mean postreinforcement pauses (times to respond on the food key) ranged from 21 to $46 \mathrm{sec}$ across birds, and were typically longer for intervals in which there were no control-key responses.

Over the first few sessions of the control-key procedure, two birds in Group 1 (5 and 20) and one in Group 2 (Bird 52) essentially stopped terminating $\mathrm{S} \Delta$ segments. The other two birds in Group $1(6$ and 22) decreased their use of the control key more gradually, but by the end of the study they were pecking it infrequently and spending most of the available time in the presence of the negative stimulus. This was also the case for Bird 58, on both the mixed and multiple schedules. Bird 54 started the experiment under the mixed-schedule condition, and during early sessions terminated a large proportion of segments; however, at midcondition, control-key responding declined sharply and remained low. When the multiple schedule was introduced in Condition 3, Bird 54 was pecking the control key on about $80 \%$ of intervals by the second session, and continued to do so throughout the condition. Bird 53 showed a similar pattern of control-key performance on both mixed and multiple schedules, initially responding on a small number of intervals, but gradually increasing the number of control-key pecks until it was terminating about $70 \%$ of segments.
The average time to respond on the control key was typically quite long, with a mean latency of $10 \mathrm{sec}$ or greater; no responses occurred immediately following food presentation. There were no systematic changes in latency across sessions, although there was a tendency for latencies to be somewhat longer during sessions when few control-key responses occurred. The fact that the birds did not respond early in intervals is somewhat surprising, since a response at this time would reduce the interreinforcement interval to about half its original length, and thus double the rate of reinforcement. The behavior observed, however, is not inconsistent with the findings of the previous experiment, and supports the view that pecking is inhibited in the immediate postfood period on FI schedules.

Although responses on the control key usually did not occur until part way through an interval, Birds 53 and 54 did terminate a substantial number of $\mathrm{S} \Lambda$ periods. In order to specify the factors maintaining control-key responding, a final experiment, in which control responses changed the stimulus on the food key from $\mathrm{S}^{\Delta}$ to $\mathrm{S}^{\mathrm{D}}$, but did not shorten the interreinforcement interval, was carried out. In Experiments 1 and 2, pecks on the control key resulted in a higher overall rate of reinforcement by reducing the duration of the interval. In addition, in the multiple-schedule conditions a negative visual stimulus was replaced with a positive, and probably secondarily reinforcing, stimulus. In Experiment 3, only the change in visual stimuli occurred; interval duration was not reduced by pecks on the control key.

\section{EXPERIMENT 3}

\section{Method}

\section{Subjects}

Three adult Silver King pigeons, with previous experience in matching-to-sample experiments, and one White Carneau pigeon (Bird 38), with some interval-schedule experience, were maintained at approximately $80 \%$ of their free-feeding weights throughout the experiment.

\begin{abstract}
Apparatus
The experiment was carried out in a standard two-key Lehigh Valley operant conditioning chamber. The left (control) key could be illuminated with white light, and the right (food) key with either red or green light from bulbs mounted behind the keys. Pecks on the right key occasionally resulted in 2-sec access to mixed grain. The chamber was illuminated with a dim houselight, except during food presentation, when the houselight and the key lights were extinguished and the only illumination was from a light over the feeder. Scheduling and recording equipment was in an adjacent room. Data were recorded on digital counters and a cumulative recorder. During some sessions, latencies of controlkey responses and postreinforcement pauses were recorded on printing counters.
\end{abstract}

\section{Procedure}

During the first session, the birds were placed in the chamber and, when necessary, given shaping by the method of successive 
Table 3

Percent of Time in the First 30-Second Segments of Intervals $\left(S^{\triangle}\right)$, Percent $S^{\Delta}$ Segments Terminated by a Control-Key Response and Total Number of Control-Key Responses (in Parentheses), Mean Latency of Responses on the Control Key, Range of Daily Mean Latencies of Control-Key Responses, and Time to the First Response in an Interval on the Food Key (Postreinforcement Pause)

\begin{tabular}{|c|c|c|c|c|c|}
\hline Birds & $\%$ Time $S^{\Delta}$ & $\begin{array}{c}\% \mathrm{~S}^{\Delta} \text { Segments } \\
\text { Terminated }\end{array}$ & $\begin{array}{l}\text { Mean Response } \\
\text { Latency* }\end{array}$ & $\begin{array}{l}\text { Range Daily } \\
\text { Mean Latencies* }\end{array}$ & $\begin{array}{l}\text { Postreinforcement } \\
\text { Pause* }\end{array}$ \\
\hline \multicolumn{6}{|c|}{ Experiment 2} \\
\hline $\begin{array}{r}5 \\
6 \\
20 \\
22\end{array}$ & $\begin{array}{r}100 \\
86 \\
100 \\
98\end{array}$ & $\begin{array}{c}0 \\
23(52) \\
0 \\
4(8)\end{array}$ & $\begin{array}{l}12 \\
21\end{array}$ & $\begin{array}{r}8-20 \\
16-30\end{array}$ & $\begin{array}{l}38 \\
31 \\
42 \\
38\end{array}$ \\
\hline \multicolumn{6}{|c|}{ Group 2** } \\
\hline $52 \begin{array}{l}\text { (mult) } \\
\text { (mix) } \\
53 \begin{array}{l}\text { (mult) } \\
\text { (mix) }\end{array} \\
54 \begin{array}{l}\text { (mult) } \\
\text { (mix) }\end{array} \\
58 \begin{array}{l}\text { (mult) } \\
\text { (mix) }\end{array}\end{array}$ & $\begin{array}{r}100 \\
100 \\
61 \\
62 \\
67 \\
92 \\
98 \\
99\end{array}$ & $\begin{array}{l}0 \\
0 \\
74(162) \\
71(156) \\
80(179) \\
13(29) \\
6(14) \\
3(7)\end{array}$ & $\begin{array}{l}14 \\
14 \\
19 \\
16 \\
23 \\
23\end{array}$ & $\begin{array}{l}12-15 \\
13-15 \\
12-22 \\
13-18 \\
16-28 \\
10-29\end{array}$ & $\begin{array}{l}40 \\
46 \\
30 \\
30 \\
22 \\
21 \\
34 \\
26\end{array}$ \\
\hline $\begin{array}{l}38 \\
39 \\
47 \\
49\end{array}$ & $\begin{array}{r}90 \\
60 \\
100 \\
73\end{array}$ & $\begin{array}{l}\text { Experime } \\
28(69) \\
67(168) \\
0(1) \\
49(122)\end{array}$ & $\begin{array}{l}19 \\
12 \\
13\end{array}$ & $\begin{array}{l}17-21 \\
10-14 \\
\\
12-15\end{array}$ & $\begin{array}{l}34 \\
17 \\
35 \\
28\end{array}$ \\
\hline
\end{tabular}

Note-Data are means over five sessions at the end of conditions. *In seconds. **Data from Conditions 2 and 3 are shown; the data from the multiple (mult) schedule are presented first irrespective of the order in which the birds received the two conditions.

approximations until they were responding consistently on the white left key. On the next day, the experiment proper began. Each daily session consisted of $501-\mathrm{min}$ intervals, each programmed as two 30-sec segments. Red and green lights, on the right (food) key, were associated with first $\left(S^{\Lambda}\right)$ and second $\left(S^{D}\right)$ segments of the interval, respectively; the key light changed from red to green automatically after $30 \mathrm{sec}$, and remained green until the first response after the interval had timed out. During this first condition, the left key was dark and inoperative. The birds continued in Condition 1 until they were showing stable fixed-interval performance: Bird 38 received 19 sessions, Birds 47 and 49, 26 sessions, and Bird 39,33 sessions.

During Condition 2, the left (control) key was illuminated with white light during the first 30 -sec segment of intervals. Pecks on this key turned off the white key light and changed the color of the right key from red to green. The duration of the interreinforcement interval was not reduced, so, on intervals when the control key was pecked, time in the presence of the green key light $\left(\mathrm{S}^{D}\right)$ increased. Bird 38 received 47 sessions in Condition 2, Bird 39, 28 sessions, Bird 47, 34 sessions, and Bird 49, 35 sessions.

\section{Results and Discussion}

All birds pecked the control key on a large percentage of intervals when it was first introduced. The number of control-key pecks decreased across sessions, so that by the end of the condition a much smaller proportion of intervals contained control-key pecks. Control-key performance is summarized in Table 3; data are means over the last five sessions of Condition 2. Bird 47 made only one control-key peck, with a latency of $16 \mathrm{sec}$, during this period, so it does not show up in the averages. The other birds pecked the key more frequently, but, as was the case with the birds in the previous study, the average latency to respond on the control key was quite long, and the percent time spent in the presence of $S^{\Delta}$ was substantial. Thus, on this schedule also, a postfood inhibitory period was observed during the initial seconds of each interval.

The results of this study support the view that the period immediately following reinforcement on FI schedules is inhibitory, at least with respect to keypecking behavior. They also suggest that a change in the stimulus on the food key, from SA to SD, is sufficient to maintain responding on the control key. Although the data from the present study do not permit us to decide whether the animal is escaping from $\mathrm{S}^{\Delta}$ or producing $\mathrm{SD}$, the findings of Leyland and Honig (1975), for a typical mult EXT VI schedule, suggest that the secondary reinforcing effects associated with the onset of $\mathrm{SD}$ maintain control-key responding.

\section{GENERAL DISCUSSION}

Schneider (1969) suggested that the stereotyped pause-and-run pattern of behavior observed on FI reinforcement schedules is best represented as a twostate process involving an extinction phase followed by a period of VI-schedule responding. In Experiments 1 and 2, pigeons were given the opportunity to peck a control key to terminate the extinction state on FI schedules. This interval-control response 
usually resulted in a change in visual stimuli, as well as a decrease in the interreinforcement interval, and its correlated increase in reinforcement rate. Nevertheless, especially on the FI 1-min schedule, the birds did not respond on the control key efficiently; controlkey responses rarely occurred until several seconds in the interval had elapsed, so that a substantial change in the rate of reinforcement did not occur. In fact, the results of Experiment 3 suggest that the responsedependent change in key color was sufficient to maintain the control-key response (see also Leyland \& Honig, 1975). Experiment 1, on the other hand, suggests that, at least on the FI 4-min schedule, proximity to reinforcement plays a considerable role. During the second, third, and fourth $S \Delta$ segments, the response occurred with decreasing latencies, although its immediate consequences in terms of changing the color on the food key were always the same. The response was more strongly maintained in the later segments either because of a shorter delay of food reinforcement or because the later SD segments were more powerful secondary reinforcers than the earlier ones. We have no data available at this time to distinguish between these possibilities.

The failure of birds to make a control-key response until some time after food presentation suggests that there are two phases to the extinction state on FI schedules. The first phase involves a period immediately following food presentation, during which pecking, and possibly other behavior, is actively inhibited. It is impossible to determine from this present study exactly what types of behavior are inhibited at this time, but as Staddon and Simmelhag (1971) have suggested, food-related responses may be suppressed and activities corresponding to other motivational systems facilitated immediately following food presentation.

Data from other studies support the view that pecking behavior, at least, is suppressed for some time following food presentation. The interval-initiating response on response-initiated FI schedules is always preceded by a pause (Chung \& Neuringer, 1967; Mechner et al., 1963; Shull, 1970), and responses to escape from stimuli associated with FI schedules seem to occur some time after reinforcement (see Figure 5 of Brown \& Flory, 1972).

In the experiments reported here both the terminal food-related response and the control-key response involved a keypeck. It would be expected that foodkey pecking would be suppressed early in the fixed interval; perhaps the control-key response is also suppressed because of its topographical similarity to that response, and to the behavior of eating (Moore, 1973; Reberg et al., 1978). This possibility could be tested by providing pigeons with another type of response, for example treadle pressing, with which to control schedule duration or terminate $S^{\Delta}$. If such behavior is also suppressed, it would suggest that the relation of the response to reinforcement, rather than its topography, is crucial.

The question of which responses are suppressed during the initial phase of the postreinforcement pause is related to the issue of which responses are likely to occur. Staddon and Simmelhag's (1971) analysis suggests that the most probable behaviors are those related to motivational states other than those associated with the primary reinforcer; for example, concurrent drinking in pigeons (Dale, 1979), schedule-induced drinking in rats (Falk, 1966), and aggression in pigeons (Flory, 1969) have been reported to occur early in fixed intervals.

The initial inhibitory phase on FI schedules is followed by a second phase of the FI extinction state, the properties of which have not been clearly identified. It is defined by a change in the postreinforcement behavior patterns before resumption of keypecking. Dale (Note 1) observed behaviors such as grooming, rearing, and walking around the chamber between the end of a bout of drinking and the onset of the terminal response on FI schedules in rats and pigeons. Staddon and Ayres (1975) reported wheel running in rats between the interim and terminal responses on fixed-time schedules. Staddon (1977) has labeled these midinterval activities "facultative behavior" and suggests that they are not scheduleinduced; that is, they are not facilitated by the reinforcement schedule.

Perhaps the control-key response in this present study indicates the end of the interim period, with its associated schedule-induced behaviors, and the onset of a facultative period during which other behaviors are free to be expressed. If this is so, there are important implications for a motivational analysis of the postreinforcement pause on FI schedules. Socalled emotional responses such as wing-flapping (Terrace, 1966) and attack (Azrin et al., 1966), which have been suggested to reflect the aversive nature of extinction, may simply be schedule-induced responses, like drinking. Such responses, which reflect nonfoodrelated motivational states that are facilitated at this time, may occur if the appropriate environmental supports are available. The research reported here supports the view that these behaviors are not necessarily by-products of an aversive extinction state. If the immediate postreinforcement period were aversive, a control-key response should occur at this time. Since control-key responses do not occur until later in the interval, during the facultative phase, we must conclude that it is at this time that the animal comes under the control of the aversive properties of the schedule. The performance of pigeons on conjunctive FR 1 FT schedules (e.g., Staddon \& Frank, 1975) is also consistent with this interpretation. On these schedules, birds typically display a pause-respond- 
pause pattern of keypecking behavior, which may reflect an initial inhibitory phase followed by a period in which the properties of the prescribed schedule gain control.

Extinction components in ordinary multiple schedules do not seem to fall into two functionally distinct phases. As mentioned previously, on mult EXT VI schedules the responses that terminate $S \Delta$ occur early in every $\mathrm{S} \Delta$ component, defining the entire period as aversive. In such schedules, reinforcement is usually programmed at variable locations within the SD periods; it does not occur just prior to $\mathrm{S} \Delta$. Reinforcement is not followed by a pause in food-key responding when variable-interval schedules are used, and it is hardly surprising that there is no suppression of control-key responding either. The pattern of other behaviors during $S^{\Delta}$ periods has not been carefully analyzed, but it is not evident at this time that interim and facultative behavior phases can readily be distinguished.

\section{REFERENCE NOTE}

1. Dale, R. H. I. Personal communication, 1976.

\section{REFERENCES}

Azrin, N. H., Hutchinson, R. R., \& Hake, D. F. Extinctioninduced aggression. Journal of the Experimental Analysis of Behavior, 1966, 9, 191-204.

Brown, T. G., \& Flory, R. K. Schedule-induced escape from fixed-interval reinforcement. Journal of the Experimental Analysis of Behavior, 1972, 17, 339-403.

Chung, S. H., \& Neuringer, A. J. Control of responding by a percentage reinforcement schedule. Psychonomic Science, 1967, 8, 25-26.

DALE, R. H. I. Concurrent drinking by the pigeon on fixedinterval food reinforcement schedules. Physiology \& Behavior, 1979 , in press.

DEws, P. B. The effect of multiple $S \Delta$ periods on responding on a fixed-interval schedule. Journal of the Experimental Analysis of Behavior, 1962, 5, 369-374.

Falk, J. L. Schedule-induced polydipsia as a function of fixed interval length. Journal of the Experimental Analysis of Behavior, 1966, 9, 37-39.

FERSTER, C. B., \& SKInNER, B. F. Schedules of reinforcement. New York: Appleton-Century-Crofts, 1957.
FLORY, R. Attack behavior as a function of minimum inter-food interval. Journal of the Experimental Analysis of Behavior, 1969 , 12. 825-828.

Honig, W. K., Beale, I. L., Seraganian, P., Lander, D. G., \& MUIR, D. Stimulus and response reduction: Two aspects of inhibitory control in learning. In R. A. Boakes \& M. S. Halliday (Eds.), Inhibition and learning. London: Academic Press, 1972.

LEYLAND. C. M., \& HoNIG, W. K. Maintenance of behavior controlling the duration of discriminative stimuli. Journal of the Experimental A nalysis of Behavior, 1975, 24, 207-214.

Mechner, F., GueVrekian, L., \& Mechner, V. A fixed interval schedule in which the interval is initiated by a response. Journal of the Experimental Analysis of Behavior, 1963, 6, 323-420.

Moore, B. R. The role of directed Pavlovian reactions in simple instrumental learning in the pigeon. In R. A. Hinde \& J. Stevenson-Hinde (Eds.), Constraints on learning. London: Academic Press, 1973.

Reberg, D., Innis, N. K.. Mann, B., \& Eizenga, C. "Superstitious" behaviour resulting from periodic response-independent presentations of food and water. Animal Behaviour, 1978, 26, 507-519.

Richards, R. W., \& Rilling, M. Aversive aspects of a fixedinterval schedule of food reinforcement. Journal of the Experimental Analysis of Behavior, 1972, 17, 405-411.

Rilling, M. E., Askew, H. R., Ahlskog, J. E., \& Kramer, T. J. Aversive properties of the negative stimulus in a successive discrimination. Journal of the Experimental Analysis of Behavior, 1969, 12, 917-932.

SChNeIDER, B. A. A two-state analysis of fixed-interval responding in the pigeon. Journal of the Experimental Analysis of Behavior. $1969,12,677-687$.

SHurl, R. L. A response-initiated fixed-interval schedule of reinforcement. Joumal of the Experimental Analysis of Behavior, $1970,13,13-15$.

Staddon, J. E. R. Schedule-induced behavior. In W. K. Honig \& J. E. R. Staddon (Eds.), Handbook of operant behavior. Englewood Cliffs: Prentice-Hall, 1977.

Staddon, J. E. R., \& Axres, S. L. Sequential and temporal properties of behavior induced by a schedule of periodic food delivery. Behaviour, 1975, 54, 26-49.

Staddon, J. E. R., \& Frank, J. A. The role of the peck-food contingency on fixed-interval schedules. Journal of the Experimental Analysis of Behavior, 1975, 23, 17-23.

Staddon, J. E. R., \& Simmelhag, V. L. The "superstition" experiment: A reexamination of its implications for the principles of adaptive behavior. Psychological Review, 1971, 78, 3-43.

Terrace, H. S. Stimulus control. In W. K. Honig (Ed.), Operant behavior: Areas of research and application. New York: Appleton-Century-Crofts, 1966.

(Received for publication June 1, 1978; revision accepted August 4, 1978.) 